\title{
Using Children's Drawings to Elicit Feedback on Interac- tive Museum Prototypes
}

\author{
Emma Nicol \\ Department of Computer and Information Sciences \\ University of Strathclyde \\ Glasgow, G1 1XH, UK \\ emma.nicol@cis.strath.ac.uk
}

\author{
Eva Hornecker \\ Department of Computer and Information Sciences \\ University of Strathclyde \\ Glasgow, G1 1XH, UK \\ eva.hornecker@cis.strath.ac.uk
}

\begin{abstract}
In this paper we describe our experience of designing and running a user evaluation of early prototypes of digital installations prior to their deployment in a new national heritage museum. Children, their parents, siblings and friends were invited to participate in the study, We focus on the effectiveness of using children's drawings to elicit responses from the child participants. Drawings provided us with insight into children's experience of the installations. Moreover, they proved a useful entry point for interviewing young children, avoiding some of the known challenges in this.
\end{abstract}

\section{Categories and Subject Descriptors}

H.5.2 [Information Interfaces and Presentation]: User Interfaces - Evaluation/Methodology

\section{General Terms}

Human Factors.

\section{Keywords}

Children, evaluation, museums, touchscreens, families.

\section{INTRODUCTION}

A visit to a museum is an inherently social activity with visitors often going there to have a day out with family or friends [6]. In this sense, playful museum installations can be considered as being akin to video or party games, which are often play tested in livingroom-like labs to study how players share control and communicate [5]. We conducted user studies of early prototypes of museum installations aimed at children and young people for a new museum. There is relatively little literature on the evaluation of museum installations, so this presented us with a challenge in terms of choosing the correct setting and the best methodology to employ. Recent museum studies literature has highlighted the role of family and parent-child interactions in museums, with parents explaining, pointing things out and asking questions [6,9]. Thus we were keen to work towards a methodology that would uncover not only usability issues, but that would also allow us to discover the children's opinions, the parents' point of view and investigate the experience of children and their adult companions in interacting with the installations as a social group. Ideally a museum exhibit would undergo user-testing in-situ in the museum itself, but this is difficult in the case of early prototypes, which may not yet

Permission to make digital or hard copies of all or part of this work for personal or classroom use is granted without fee provided that copies are not made or distributed for profit or commercial advantage and that copies bear this notice and the full citation on the first page. To copy otherwise, or republish, to post on servers or to redistribute to lists, requires prior specific permission and/or a fee.

IDC 2012, June 12-15, 2012, Bremen, Germany.

Copyright 2012 ACM 978-1-4503-1007-9...\$10.00. be fully functioning. Running studies in a "space of intermediate authenticity" might give a good sense of how groups would interact [1], thus we decided to conduct our research within a museum space, and not just with individual child users, but with the social groups that would typically visit a museum.

Evaluating interactive systems with young children is challenging, since standard methods and techniques may be inappropriate when dealing with this age group. In particular, young children are notoriously hard to interview, as they try to please adults, are easily distracted, and have difficulty expressing their likes and dislikes [3]. Capturing experiences by asking children to produce drawings has been demonstrated to be an effective technique [7, $11,12]$. Drawings have the advantage of being a quick and efficient way to elicit a large amount of accurate information as no training or practice is required [7]. Also, drawings are generally easily produced by children who cannot write proficiently (if at all) and provide a means of expression for those children who would have difficulty in doing so verbally to a researcher. Not all experiences are easily expressed by words alone [11, 12]: drawings can allow for an additional richness to emerge. We investigated how the use of drawings could be combined with other evaluation tools in a study of digital museum installations prototypes. Our study differs from previous studies that have used the drawings method both in terms of setting, and in the presence of parents in the interaction and evaluation process.

\section{BACKGROUND}

In spring 2010 we were commissioned by the National Trust for Scotland (NTS) to conduct formative user studies of early prototypes of digital interactive installations that had been specially commissioned for the new Robert Burns Birthplace Museum in Alloway, Scotland. The museum houses a collection of artefacts and belongings from the poet Burns's life as well as editions of his collections of poetry. The museum encourages curiosity and playful interaction from its visitors and is designed with familyfriendliness in mind. The installations all had the character of short games or playful engagements with themes around Burns.

\subsection{Study Overview}

We enlisted young families for the evaluation sessions, testing each installation with at least 8 separate groups. During the summer of 2010 we successively received the prototypes from the developers, and ran each sub-study within a 2 -week framework. Each resulted in a report on usability issues, participants' likes and dislikes, and detailed suggestions for improvement for further iterations of the games. Much of this is detailed in [2]. While ideally we would have liked to evaluate the games in the museum itself, because it was at this time being rebuilt, we configured the installation setup to replicate as far as we could what visitors would meet in the museum. 


\subsection{The Games}

We had 4 games to evaluate, each having the form of a minigame. For the purposes of this paper we focus on three touchscreen based installations, and one table-top game, all primarily aimed at children and teenagers.

PhotoFit is a touchscreen-based game based around the physical appearance of Robert Burns. Players are invited to construct a photofit type image of Burns by selecting different combinations of eyes, mouth, nose, ears and hairstyle from available features. Text quotes that describe Burns' appearance appear on the screen to aid the selection. In the end, when a face has been completed, it then appears as an image on a tin of shortbread biscuits.

The Poetry Game asks players to beat out the rhythm of a poem recited aloud by a male voice. There are 2 different poems to choose from: "Tam O'Shanter" and "To a Mouse". The text of each poem moves across the screen as the audio plays. Rhythm points are marked by pieces of cheese above the appropriate word. Pressing a button makes a mouse-shaped sprite jump up to eat the cheese. Points are awarded for each piece of cheese caught. At the end, the full text of the poem is displayed.

The Spooky Stories (Figure 1) game is based around the poem "Tam O'Shanter" wherein a man on his way home at night encounters witches and other spooky creatures and is pursued by these through his village. The game shows a village background scene and a virtual transparency of spooky figures that can be pressed out onto the scene and then moved around within it. When all the figures are in place, the figure of Tam walks through the village.

The Burns Supper Table game was different in several ways. Players stand around a round table pressing buttons to play it. The game in play is projected onto the table from above, and consists of five mini-games. These mimic the traditions of the annual Burns supper. One game, for example, involves using a virtual knife to stab at haggis that swirl through the scene. Points are awarded for each successful stab and each stabbed haggis emits a "squishing" noise. Another game involves pressing a button to make bagpipes play the notes of a melody of a Burns song.

\section{METHODOLOGY}

While unable to test in the museum itself, we were still keen to recreate some of the dynamics of a museum setting to lend some authenticity to the space [1] in which we conducted our study. We situated our study in the Kelvingrove Museum in Glasgow, a large, free-entry museum that most of our participants had visited before. We set up our equipment in a relatively quiet corner of the museum, a Reading Room where visitors can consult books or access information online.

\subsection{Experimental setup}

We tried to emulate the final setup in the museum as far as possible, knowing the influence that contextual and technical setup can have on usability and social experience of play $[4,10]$ The touchscreen was of comparable size to the final installations (20"). It was set at a height and at the angle that would be encountered in the Burns museum such that both small children and their parents could play with it (Figure 1). We set up a video camera above the interaction that the participants were made aware of and created a space nearby full of large pieces of paper, pens and coloured pencils, where participants could create their drawings. For logistical reasons we could not test the Burns Supper Table game here, instead we did this in our research lab at the university. Using Ar- duino we mocked up a table to the approximate specifications provided the NTS and added pressable buttons. In our lab we also had a separate art table available for children to do their drawings.
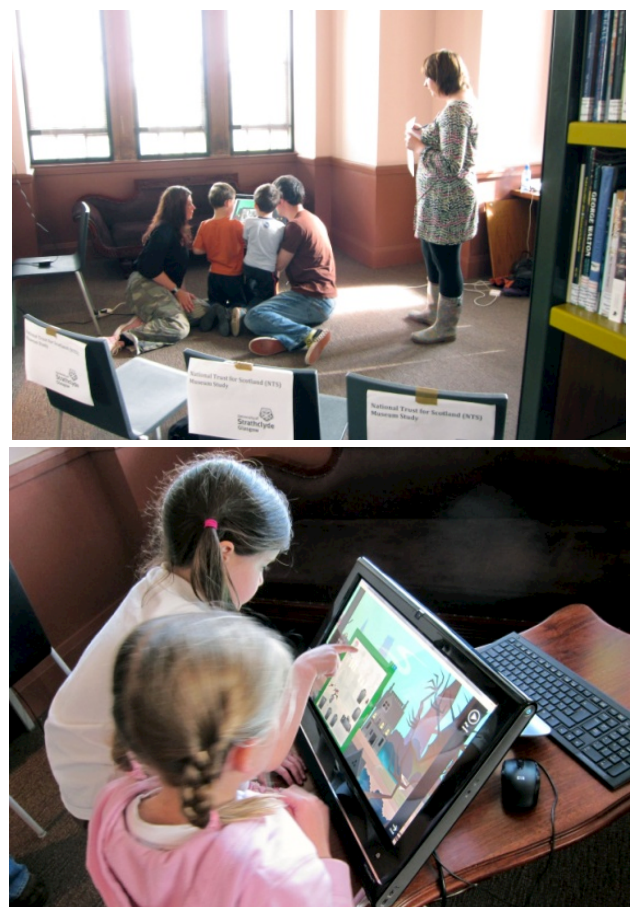

Figure 1. Trial setup in the museum, with researcher observing and taking notes. Children play 'Spooky Stories' game.

\subsection{Participants}

Some participants were recruited in the museum, though mostly recruitment was done via email, posters and snowballing among friends and relatives of participants. Each installation was tested with 8-10 family groups that varied in size between adult-child pairings (around half the groups), to one group that consisted of an adult and 4 children. Where there was more than one child in a group these were siblings or friends. All child participants were from the UK. All children had English as their first or bilingual spoken language. The NTS had recommended that we evaluate with children aged 5-12. In practice, while the majority of child participants fitted this description, a number of children fell just outside this age range (siblings being brought along) but were nonetheless willing and able to participate in the games in some way. While some studies caution against using siblings together in evaluations [8] this appeared to be appropriate for the purposes of studying family interaction with the devices. Participants were rewarded with vouchers for NTS properties.

When families arrived they had often already spent some time in the museum or intended to do so afterwards. They were told a bit of background about the study and the new museum, then parents completed consent forms. Without further instruction the family group was invited to "go and play" with the game [5] and allowed as many repetitions of the game as they wanted within the time frame of each evaluation session (half an hour for the hands-on interaction plus half an hour for the interview). If children found it difficult to know how to get started and parents either did not intervene or could not themselves see what to do, we did on occasion provide assistance if it was clear that no game play would en- 
sue otherwise. Up to two observers made written notes (Figure 1). When gameplay ended, adults and those children who were old enough (typically aged $12+$ ) were invited to complete a questionnaire. In the meantime children were asked to "Draw yourself playing the game". The sessions, lasting between 40-60 minutes concluded with a short interview with the children, asking them to show and explain their drawing, with parents present.

It is well known that it is very difficult to interview young children, who are often trying to please the adult asking the questions and may not be able to verbalize their experience [3,12]. We hoped that the drawings would provide us with further insight into children's experiences and furthermore that using the drawings would create a more natural and familiar situation for children for children to talk about their experience. This is what we will mostly focus on in this paper.

\section{RESULTS AND DISCUSSION}

Few children required any persuasion to complete the drawings and over the course of the 4 studies, 38 drawings were produced. In many cases it seemed drawing was as much fun as playing with the game itself. Drawings were done with real care and attention by the great majority of the children and much use was made of colour to report details of the games and setup. In a couple of cases children under 12 instead chose to complete a questionnaire with support from parents, but generally, drawings were highly successful. Very small children were occasionally unhappy with us keeping their drawings - in one case we had to promise to make a copy and send it to the family.

We had been concerned that parents might try to influence what children drew. Previous studies have captured children's experiences using drawings free from the immediate influence or involvement of parents [12]. In practice, adults were generally preoccupied with completing the questionnaire while their children sat apart from them in the art space drawing and there were almost no interventions from parents, even if they had been keen to scaffold during the game (though all were keen to praise the final drawings). Where more than one child was involved, children sat side by side and were allowed to talk to each other while drawing. We did not record this chat as in [12], but made frequent inspections of progress and listen for discussions. Children interacted very little, verbally or otherwise. In larger groups of children more chat was observed.

Our purpose in asking the children to produce drawings was not merely to visually judge what they might have perceived about the installations and their enjoyment in using them. Rather we used features of the drawings as a way into interviewing the children and understanding their experience while playing the game: what they had understood, misunderstood, liked or disliked about the games and how they thought they had interacted with others. In this sense we believe using drawings was a successful strategy. We began the interview by asking children to show their drawing and explain what they had drawn, sometimes pointing to specific pictorial elements to ask what they represented. Children generally talked freely about what they had drawn and there was very little shyness about doing so. A few children needed an occasional bit of encouragement from parents to speak up but these were the exception. Using the drawings as the starting point of the interview meant we could focus on what was important to the child and gain their trust in talking about something personal to them, and where they were proud to show what they had created.

Our only instruction to children before they drew was to "Draw yourself playing the game". It was tricky to find a way of express- ing this that would not be too leading, but we believe that the drawings that resulted contained the richness required in order to conduct a successful interview thereafter. Two researchers performed an analysis of the drawings following the study. In all of the drawings produced the child itself makes an appearance as does the touchscreen/table on which the games were played and in most cases the children drew not just the screen but the table and other fittings too.

Table 1. Most commonly drawn features

\begin{tabular}{|l|l|l|l|}
\hline Game & Smile & $\begin{array}{l}\text { Interface and child's depicted } \\
\text { posture, play situation }\end{array}$ & Setup \\
\hline $\begin{array}{l}\text { PhotoFit } \\
\text { (7 drawings) }\end{array}$ & 5 & $\begin{array}{l}\text { Image of face on screen (4) } \\
\text { Child seen from the front (6) } \\
\text { Family member shown (1) }\end{array}$ & $\begin{array}{l}\text { Table } \\
(3)\end{array}$ \\
\hline $\begin{array}{l}\text { Poetry } \\
\text { (10drawings) }\end{array}$ & 7 & $\begin{array}{l}\text { Child's outstretched arm (6) } \\
\text { Child seen from the side (5), } \\
\text { Child from the back (2) }\end{array}$ & $\begin{array}{l}\text { Table } \\
(6)\end{array}$ \\
\hline $\begin{array}{l}\text { Spooky Sto- } \\
\text { ries } \\
\text { (9 drawings) }\end{array}$ & 7 & $\begin{array}{l}\text { Bridge(4) Green monsters(4) } \\
\text { (plus other creatures) } \\
\text { Child shown frontal (7), from } \\
\text { back (1), from side (1) }\end{array}$ & $\begin{array}{l}\text { Table } \\
(4)\end{array}$ \\
\hline $\begin{array}{l}\text { Burns Supper } \\
\text { (12 draw- } \\
\text { ings) }\end{array}$ & 8 & $\begin{array}{l}\text { Haggis (7), Buttons (9), 'Man in } \\
\text { the middle of game' (5) } \\
\text { several players shown (6), child } \\
\text { shown frontal (10), from side (1), } \\
\text { from back (1) }\end{array}$ & $\begin{array}{l}\text { Table } \\
\text { (8) } \\
\text { Projec- } \\
\text { tor rig- } \\
\text { ging (2) }\end{array}$ \\
\hline
\end{tabular}

There were no obvious signs in the drawings that any of the children felt badly about their performance. In 27 of the 38 drawings analyzed, children drew themselves smiling. The most commonly drawn features (see Table 1) in both the Photofit game and the Spooky Stories game were characters that appeared on the screen. This is perhaps unsurprising given that the task in each involves the selection of pictorial elements to create a visual scene. By contrast, the Poetry game gave rise to drawings that emphasize the posture of the child playing the game (Figure 2) rather than the action on screen, a reflection we think of the time-pressed and focused nature of the interaction in this game which required frantic button pressing.

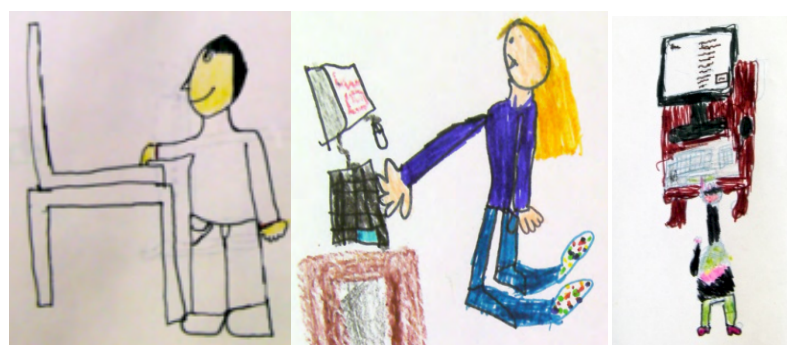

Figure 2. Children drawing themselves playing the Poetry Game from the side or back (note the stretched out arms)

Also, children much more frequently drew themselves playing the Poetry Game from the side or the back, whereas children who had played PhotoFit and Spooky Stories tended to draw themselves standing next to the screen, pointing to it, reflecting the 'look I made this' nature of the games (see Figure 3). The frequent appearance of the haggis in the drawings of the Burns Supper game (Figure 4) correlates with our observation that this section of the game was the one that participants generally found the most engaging. 


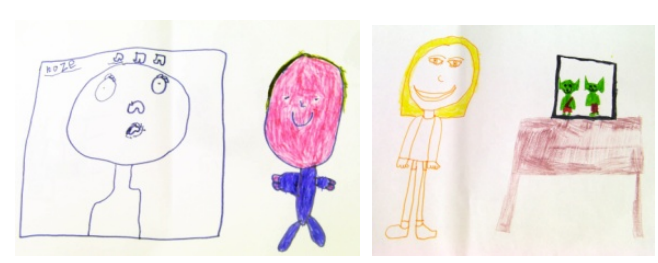

Figure 3. Examples of Photo Fit and Spooky Stories drawings
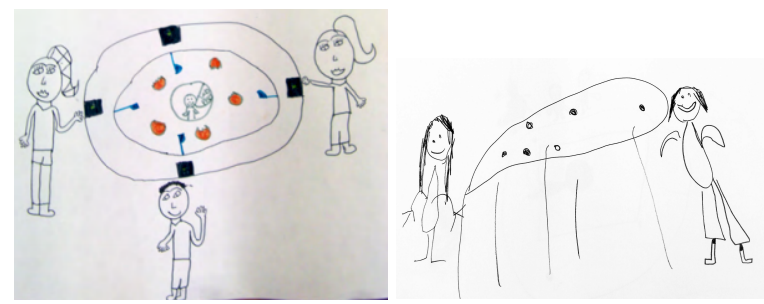

Figure 4. Burns Supper Table: (left) stabbing the haggis.

Children were observed to play the three touchscreen games with (or against!) other children and adults (sometimes playing turn by turn or verbally negotiating which element to choose next). In some cases this lead to conflict as in the Spooky Stories game, where children sometimes pushed the hands of others away, but this did not make its way into the drawings. In only 1 of the 26 drawings of the touchscreen games does another human figure appear. The drawings of the Burns Supper table game show a marked difference in this regard (Figure 4). The children tended to draw not just themselves in the game but also the other players. In 6 out of 10 cases other figures were drawn. Given that the drawing instruction had been exactly the same as the same as for the touchscreen games we believe that this is an indication that the children perceived this game differently from the others and regarded it is a group-based activity. This accurately reflects the game nature, which, while it can be played in single-player mode, is designed to be played by groups.

The drawings were used as a entry point to interviewing children about their experience. Here, a 5 year old talks about Photofit. The first question was one that we used to start every interview: Can you tell me what's in your picture? That's me. That's my hair! It's spiky hair. How do you feel in the picture? Happy. Cos it's a great game. You make Robert Burns' face. Why was it great? Because you put in whatever you want. But you need to put in matching eyes.

The child clearly shows pride in his drawing and is happy to talk about it. Here, as was the case for several of the interviews, the child emphasises the fun that came from creating silly combinations of facial features rather than recreating Burns' true likeness. This confirmed our impression from observations. Once children had begun talking about their drawings, it was easy to move on to questions about other issues such as how to improve the games. Some children even drew their suggested improvements. The drawings were also useful in keeping children focused on the interview.

\subsection{Limitations}

Questions remain about how to frame the instructions to participants when asking them to draw their activities. It is possible that because the drawing activity happens after the evaluated activity, it may be the experience of doing the drawing that is being reported during the subsequent interview rather than the experience of playing the game.
Aside from the drawings the user studies could not of course replicate the full social dynamics of a museum.

\section{CONCLUSION}

We believe our user studies were successful in evaluating collaborative games and were effective in both identifying usability issues (see [2] for details) and uncovering the nature of the user experience of the gameplay. Our study indicates that using the drawings method to elicit responses in an interview situation is an effective methodology for performing an evaluation of early prototypes of a system designed for museum entertainment. Drawings provided useful insight into what children had focused on in the games and how they experienced the gameplay, as well as providing us with an 'entry point' for interviewing children. The presence and influence of parents on feedback can be partly mitigated by using an appropriate study design. The use of drawings alone may not be enough to uncover usability issues: observations may also be required.

\section{ACKNOWLEDGMENTS}

We thank the NTS, Kelvingrove Museum and the participants.

\section{REFERENCES}

[1] Gutwill, J.P., Allen, S. 2010. Group Inquiry at Science Museum Exhibits. Getting Visitors to Ask Juicy Questions. Exploratorium /Left Coast Press 2010.

[2] Hornecker, E., Nicol, E. 2011. Towards the Wild: Evaluating Museum Installations in Semi-Realistic Situations. In Proc. of Re-thinking Technology in Museums Conf. 2011.

[3] Hourcade, J.P. 2007. Interaction Design and Children. FnT in HCI Vol. 1, No. 4, 277-392.

[4] Isbister, K. 2010. Enabling Social Play. A Framework for Design and Evaluation. In: Bernhaupt, R.(ed) Evaluating User Experience in Games. Springer.

[5] Isbister, K., Schaffer, N. 2008. Game usability: advancing the player experience. Morgan Kaufmann.

[6] Kelly, L., Savage, G., Griffin, J., Tonkin, S. 2004. Knowledge Quest: Australian Families Visit Museums. Australian Museum and National Museum of Australia.

[7] MacPhail, A., Kinchin, G. 2004. The use of drawings as an evaluative tool: students' experiences of Sport Education. Physical Education and Social Science, 9(1): p. 88-108.

[8] Rounding, K., Tee, K., Wu, X., Guo, C., Tse, E. 2011. Evaluating Interfaces with Children, In Child Computer Interaction. 2nd Workshop on UI Technologies and Educational Pedagogy. At ACM CHI.

[9] Sanford, C., Knutson, K., Crowley, K. 2007. We Always Spend Time Together on Sundays": How Grandparents and Their Children Think About Use and Informal Learning Spaces. Visitor Studies 10: 2, 136-51.

[10] Snibbe, S., Raffle, H. 2009. Social Immersive Media- Pursuing best practices for multi-user interactive camera/projector exhibits. In Proc. of CHI 09, ACM.

[11] Sylla, C., Branco, P., Coutinho, C., Coquet, M.E. 2009. Storytelling through Drawings: Evaluating Tangible Interfaces for Children. In Extended Abstracts CHI 2009, ACM.

[12] Xu, D., Read, J.C., Sim, G., McManus, B. 2009 Experience It, Draw It, Rate It - Capture Children's Experiences with Their Drawings. In Proc. of IDC 09, ACM: NY. 